\title{
Respiratory and peripheral muscle involvement in patients with pulmonary arterial hypertension due to congenital heart diseases
}

\author{
Özge Keniş-Coşkun¹, Derya Kocakaya ${ }^{2}$, İlker Yağci'1, Bülent Mutlu ${ }^{3}$, Sait Karakurt ${ }^{2}$ \\ ${ }^{1}$ Marmara University Medical Faculty, Physical Medicine and Rehabilitation Department, Istanbul; ${ }^{2}$ Marmara \\ University Medical Faculty, Pulmonology Department, Istanbul; ${ }^{3}$ Marmara University Medical Faculty, Cardiology \\ Department, Istanbul, Turkey
}

\begin{abstract}
Skeletal and respiratory muscle dysfunction has been previously described in patients with other etiologic subgroups of pulmonary arterial hypertension (PAH) but has never been investigated in patients with PAH due to congenital heart diseases (CHD). This study aims to show the involvement of skeletal and respiratory muscles in these patients. This cross-sectional study included patients with PAH due to CHD and healthy controls. Patients' demographic properties, six-minute walk tests; shoulder abduction, handgrip, knee extension, and ankle dorsiflexion muscle
\end{abstract}

Correspondence: Ozge Kenis-Coskun, Marmara Universitesi Egitim ve Arastirma Hastanesi, Pendik, Istanbul, Turkey.

Tel. +90.5058294947.

E-mail: ozgekenis@gmail.com

Contributions: OKC, research design, data acquisition, writing, and editing of the paper; DK, research design, data acquisition, writing, and editing of the paper; IY, data acquisition, writing, and editing of the paper; BM, writing and editing of the paper; SK, research design, writing, and editing of the paper.

Conflict of interest: The authors declare that they have no competing interests, and all authors confirm accuracy.

Ethics approval and consent to participate: This study has been approved by the Local Ethical Committee and all the participants have given their written informed consent.

Availability of data and materials: The data of this study are available from the corresponding author on request.

Key words: congenital heart disease; pulmonary hypertension; skeletal muscle; ultrasound.

Received for publication: 6 August 2020

Accepted for publication: 1 December 2020.

${ }^{\circ}$ Copyright: the Author(s), 2021

Licensee PAGEPress, Italy

Monaldi Archives for Chest Disease 2021; 91:1551

doi: 10.4081/monaldi.2021.1551

This article is distributed under the terms of the Creative Commons Attribution Noncommercial License (by-nc 4.0) which permits any noncommercial use, distribution, and reproduction in any medium, provided the original author(s) and source are credited. strength, maximum inspiratory (MIP) and expiratory pressures (MEP) were measured. Deltoid, flexor digitorum superficialis, and profundus, tibialis anterior and rectus femoris muscles were visualized with ultrasonography and their cross- sectional areas (CSA) were also measured in both groups. Twelve patients and 12 controls were included. Mean MIP was $104.22 \pm 32.57 \mathrm{~cm} \mathrm{H} 2 \mathrm{O}$ for healthy participants while $61.33 \pm 29.74 \mathrm{~cm} \mathrm{H} 2 \mathrm{O}$ for patients $(p<0.001)$. For mean MEP, it was $100.08 \pm 26.05 \mathrm{~cm} \mathrm{H} 2 \mathrm{O}$ in healthy participants and $69.75 \pm 39.79 \mathrm{cmH} 2 \mathrm{O}$ in controls $(p=0.004)$. When the strength of skeletal muscles was compared, there were significant differences between the groups in all measurements except for bilateral grip strength. In the correlation analysis, MIP and MEP values showed no significant correlations with clinical parameters. They showed significant moderate correlations with skeletal muscle strength. When CSAs of the muscles were compared, there were significant differences in all measurements except for left FDS and FDP and bilateral rectus femoris. This study showed that in patients with pulmonary arterial hypertension due to $\mathrm{CHD}$, respiratory muscle strength is significantly worse than healthy participants. Patients had also significantly worse skeletal muscle strength except for grip strength.

\section{Introduction}

Pulmonary arterial hypertension (PAH) is characterized by an increase in mean pulmonary artery pressure at rest, together with increased resistance in pulmonary vascular structures, and causes right-sided heart failure. Connective tissue diseases, chronic thromboembolic pulmonary hypertension (CTEPH), and congenital heart diseases (CHD) are the leading causes of PAH. PAH associated with congenital heart diseases divided into 4 groups: Eisenmenger syndrome, PAH associated with prevalent systemic arterial to pulmonary shunts, PAH with small/coincidental defects, PAH after defect correction $[1,2]$.

It has been previously shown that respiratory muscles are affected in patients with various subgroups of PAH and CHD $[2,4]$.However, the relationship between the strength of skeletal muscle and respiratory muscles are less studied in patients with $\mathrm{CHD}$, and there are no data in patients with PAH due to CHD. The extensive population of $\mathrm{PAH}$ patients, ranging from elderly patients with CTEPH to younger patients with CHD or connective tissue diseases, make it compulsory to study each PAH group within themselves in such a context. Peripheral muscle abnormalities, including skeletal and respiratory muscles, largely contribute to the decreased quality of life and exercise capacity in patients with all subclasses of PAH [5].In this regard, showing the involve- 
ment of skeletal muscles in adults with CHD would be important in focusing on interventions to prevent a dysfunction early in the course of the disease.

The hypothesis of this study is that patients with PAH due to CHD have weaker respiratory muscles. The secondary aim is to show the relationship between respiratory and skeletal muscle strengths and ultrasound cross-sectional areas of examined muscles together with other clinical parameters.

\section{Materials and Methods}

This study has been conducted between June 2019-January 2020 in a tertiary hospital Physical Medicine and Rehabilitation and Pulmonary Vascular Diseases outpatient clinics. Patients between ages 18-55 with PAH due to CHD were included in this study that accepted to join the study protocol with informed consent. Exclusion criteria were a history of musculoskeletal surgery within the last six months, not being able to perform a 6-minute walk test (6MWT), and a history of hospital admission for cardiac decompensation within the last month. Age and sex-matched healthy volunteers without any histories of musculoskeletal and pulmonary pathology were also included in the study as a control group. All participants were chosen to be right dominant. All participants have given their written informed consent and the local ethical committee approved the study.

Patients' age, sex, height, weight, and body mass index (BMI), and their systolic pulmonary arterial pressure measured via echocardiography were recorded. Patients 6MWTs were performed according to the ATS/ERS criteria, using a 30 meters corridor [16]. Patients' and controls' skeletal muscle strengths were assessed with baseline push and pull dynamometer (Fabrication Enterprises Inc., USA) with the "break" test, where the tester firmly holds the dynamometer and applies force against the subject's body until it begins to move. The reading represents the muscle strength "break" point at which the subject could not overcome the tester's force. Shoulder abduction was measured with the patient seated, shoulder, and elbow at 90 degrees flexion while the dynamometer placed slightly above the tested upper extremity [7]. The tester positioned behind the patients with the opposite hand on the opposite shoulder. Knee extension was measured with the patient sitting, their legs over the table edge while the measured lower extremity slightly extended. The dynamometer was placed slightly above the ankle with the tester in front of the subject [8]. Ankle dorsiflexion was measured with the patient supine, and the dynamometer placed below the toe on the foot measured [7]. Patients' grip strength was measured using Jamar dynamometer (Sammons Preston, Inc., Bolingbrook, IL, USA) with the patient in sitting position, forearm neutral and the elbow flexed 90 degrees beside trunk [9]. Maximum inspiratory pressure (MIP), and maximum expiratory pressures (MIP) were measured using the MicroRPM device (Vyaire, USA) according to the ATS/ERS guidelines [10]. All measurements were done by a single researcher three times and had an intraclass correlation coefficient (ICC) ranging from 0.96-0.99 for skeletal muscle strength, 0.83 for MIP, and 0.94 for MEP. The mean value of all three measurements was used in the final analyses.

Ultrasonographic images of middle deltoid, flexor digitorum superficialis (FDS), flexor digitorum profundus (FDP), rectus femoris and tibialis anterior muscles were obtained by a blinded ultrasonographer with 10 years of experience. A General Electric ultrasound system (Loqiq 5 pro machine with a 6-18 MHz linear array probe) was used. The image settings, time gain compensation, depth, and sector size were kept constant. Minimum pressure with ample conductance gel was used to prevent altering muscle thicknesses. Patients were analyzed sitting down, facing the ultrasonographer with their upper extremities resting on their lap for the upper extremities and in supine position with knees extended and ankles on neutral position for lower extremities. The deltoid muscle was visualized 5 centimeters distal to the acromioclavicular joint bilaterally [11]. FDS and FDP were visualized at the $1 / 2$ length of the forearm [12]. Rectus femoris was visualized at the middle point between the greater trochanter and patella [13]. Tibialis anterior muscle was visualized 5 centimeters below the patella lateral to the tibia. The visualizations and the cross-sectional areas (CSAs) measured for each muscle can be seen in Figure 1.
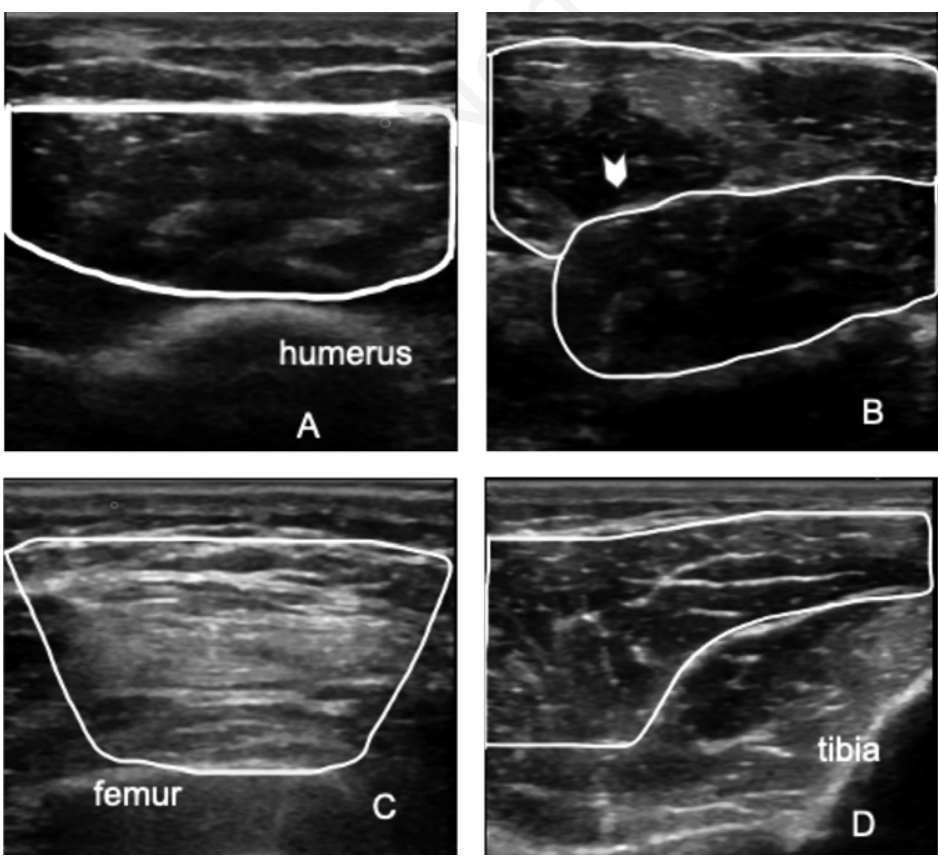

Figure 1. The muscles visualized by the ultrasound; their borders are marked with white. A) Deltoid B) Flexor digitorum superficialis and profundus C) Rectus femoris D) Tibialis anterior Arrowhead: median nerve. 


\section{Statistical analyses}

Sample sizing was performed using G power. Based on a similar study that showed a mean MIP of $80.7 \pm 26.7$ in the patient group and $111.1 \pm 29.9$ in the control group, 12 participants in each group were determined to be sufficient with an alpha of 0.05 and $80 \%$ power [14]. Basic descriptive tests were used for demographic properties. The distribution of the variables was evaluated using Shapiro-Wilks testing and Q-Q plots. Since the data were observed to be distributed normally, independent samples t-test was used to determine group differences. For correlation analyses, Spearman correlation was used despite the normality of the data due to the lack of a linear correlation. A p-alue below 0.05 was considered significant.

\section{Results}

Among a total of 35 patients that are followed with PAH due to $\mathrm{CHD}, 13$ were included in the study since they agreed to participate in it. One patient had to be excluded due to accompanying congenital upper extremity deformity. Therefore, 12 patients and 12 age and sex-matched controls were included in the final analysis. Patients' demographic properties are given in Table 1. Only one patient had accompanying type 2 diabetes mellitus. The other patients did not have any accompanying co-morbidities. Healthy participants had significantly higher MIP and MEP values. Mean MIP was $104.22 \pm 32.57 \mathrm{cmH} 2 \mathrm{O}(\min 59.67-\max 159.00)$ for healthy participants while $61.33 \pm 29.74 \mathrm{cmH} 2 \mathrm{O}(\min 35.33-\max$ $135.67)$ for patients $(\mathrm{p}<0.001)$. For mean MEP, it was $100.08 \pm 26.05 \mathrm{cmH} 2 \mathrm{O}$ ( $\min 84.00-\max 177.33)$ in healthy participants and $69.75 \pm 39.79 \mathrm{cmH} 2 \mathrm{O}(\min 23.67-\max 147.33)$ in controls $(\mathrm{p}=0.004)$. When skeletal muscles' strengths were compared, there were significant differences between the groups in all measurements except for bilateral grip strength. When CSAs of the muscles were compared, there were significant differences in all measurements except for left FDS and FDP and bilateral rectus femoris (Table 2). In correlation analyses, MIP and MEP values showed no significant correlations with clinical parameters. They showed significant moderate correlations with skeletal muscle strength. Mean MIP values did not significantly correlate with muscle CSA, while MEP showed significant moderate correlations with all muscle CSAs except rectus femoris bilaterally (Table 3).

\section{Discussion}

This study showed that in patients with PAH due to CHD, respiratory muscle strength is significantly worse than healthy participants. Considering the normal predictive values that have been defined in literature for MIP vary between 89.0 to $128.5 \mathrm{mmH} 20$ and 81.9 to $111.8 \mathrm{mmH} 2 \mathrm{O}$ for MEP, patients' values can still be considered significantly worse $[15,16]$. Patients had also significantly worse skeletal muscle strength except for grip strength. In ultrasonography, most of the muscles observed to reflect these changes by having a significantly lower CSA except for left finger flexors and bilateral rectus femoris muscles. Studies that investigate respiratory muscle strength in patients with PAH are scarce in the literature. A study conducted in patients with PAH showed that PAH patients had significantly less MIP and MEP values when compared to healthy participants [17]. The study population consisted of CTEPH and idiopathic PAH (IPAH) patients; therefore, their mean age was higher. Although their results partially support the current one, this study implements a more homogenous group of patients with PAH. In contrast, their results also showed a correlation of MIP and MEP values with the results of 6MWT, which this study failed to demonstrate. Another study showed also showed respiratory muscles are affected in patients with IPAH and correlate with clinical parameters [3]. The discrepancy between MIP/ MEP values and clinical parameters in this study can be both due to the younger patient population and better functional levels, which may show that the mechanics of respiratory muscles are spared, and the limited number of patients included in the study.

It has been previously described that pulmonary hypertension adversely affects skeletal muscle metabolism causing reduced skeletal muscle mass, reduced volitional and non-volitional contractility, reduced generated force, a fiber switch from type I to type II, increased protein degradation through ubiquitin-proteasome system activation, reduced mitochondrial functioning, and

Table 1. Patient characteristics.

\begin{tabular}{|c|c|c|c|c|c|c|c|}
\hline Patient no: & $\begin{array}{c}\text { Age } \\
\text { (years) }\end{array}$ & Sex & Diagnosis & $\begin{array}{c}\text { BMI } \\
\left(\mathrm{kg} / \mathrm{m}^{2}\right)\end{array}$ & $\begin{array}{c}\text { sPAP } \\
(\mathrm{mmHg})\end{array}$ & $\begin{array}{l}\text { NYHA } \\
\text { Class }\end{array}$ & 6-minute walk test (meters) \\
\hline 1 & 24 & M & Operated VSD & 25.25 & 35 & 1 & 553. \\
\hline 2 & 27 & $\mathrm{~F}$ & ASD & 23.23 & 30 & 1 & 510. \\
\hline 3 & 27 & M & ASD & 31.10 & 25 & 2 & 425. \\
\hline 4 & 44 & $\mathrm{~F}$ & Operated VSD & 33.30 & 45 & 3 & 354. \\
\hline 5 & 30 & $\mathrm{~F}$ & VSD & 19.10 & 20 & 2 & 412. \\
\hline 6 & 28 & M & Operated VSD & 24.39 & 30 & 2 & 448. \\
\hline 7 & 41 & $\mathrm{~F}$ & VSD & 25.53 & 55 & 2 & 418. \\
\hline 8 & 51 & M & ASD & 27.55 & 58 & 2 & 415. \\
\hline 9 & 44 & $\mathrm{~F}$ & Eisenmenger & 26.33 & 129 & 3 & 423. \\
\hline 10 & 40 & $\mathrm{~F}$ & Operated ASD & 25.00 & 32 & 2 & 479. \\
\hline 11 & 42 & $\mathrm{~F}$ & Operated ASD & 24.98 & 45 & 1 & 510. \\
\hline 12 & 40 & M & VSD & 22.66 & 110 & 2 & 444. \\
\hline
\end{tabular}

M, male; F, female; ASD, atrial septal defect; VSD, ventricular septal defect; BMI, body-mass index; sPAP, systolic pulmonary arterial pressure; NYHA, New York Heart Association. 
impaired activation-contractility coupling [18]. In addition to this, generalized muscle dysfunction can occur due to the sympathetic nervous system's continuous activation due to limited cardiac output in patients with IPAH [19]. Therefore, it is not surprising to see significantly less skeletal muscle strength in the current study as in concordance with current literature. Grip strength is also decreased in patients with IPAH and showed correlation with respiratory muscle strength [20]. When the literature about the skeletal muscle strength in patients with CHD is investigated, it shows similar results with decreased grip strength, decreased shoulder flexion strength, and decreased number of heel-lifts [14,21,22]. Contrary to the current literature, this study showed no differences between

Table 2. Differences between healthy participants and patients. All values are mean (SD).

\begin{tabular}{|c|c|c|c|c|c|c|}
\hline Parameter & $\begin{array}{l}\text { Healthy participants } \\
\qquad(\mathrm{n}=12)\end{array}$ & $\begin{array}{l}\text { Patients } \\
(\mathrm{n}=12)\end{array}$ & $\begin{array}{c}\text { Mean } \\
\text { difference }\end{array}$ & $\begin{array}{l}\text { Standard error } \\
\text { of difference }\end{array}$ & $95 \% \mathrm{CI}$ & p-value \\
\hline Age (years) & $37.25(9.44)$ & $36.50(8.78)$ & 0.75 & 3.72 & $6.97-8.47$ & 0.84 \\
\hline BMI & $27.54(4.10)$ & $25.70(3.72)$ & 1.83 & 1.6 & $1.47-5.15$ & 0.26 \\
\hline R shoulder abduction power (kg) & $10.69(1.12)$ & $5.15(2.07)$ & 5.54 & 0.69 & 4.11- 6.98 & $<0.001^{*}$ \\
\hline L shoulder abduction power (kg) & $9.91(1.29)$ & $5.27(2.23)$ & 4.64 & 0.75 & $3.07-6.21$ & $<0.001^{*}$ \\
\hline R grip power (kg) & $33.16(5.63)$ & $27.33(12.44)$ & 5.83 & 3.96 & $2.41-14.08$ & 0.15 \\
\hline L grip power (kg) & $32.16(7.11)$ & $24.90(12.85)$ & 7.25 & 4.28 & $1.64-16.16$ & 0.11 \\
\hline R knee extension power (kg) & $11.33(2.04)$ & $6.18(1.38)$ & 5.15 & 0.73 & $3.62-6.68$ & $<0.001^{*}$ \\
\hline L knee extension power (kg) & $10.91(1.71)$ & $4.57(1.12)$ & 6.34 & 0.61 & $5.06-7.61$ & $<0.001^{*}$ \\
\hline R ankle dorsiflexion (kg) & $8.36(1.38)$ & $3.27(1.11)$ & 5.08 & 0.53 & $3.99-6.18$ & $<0.001^{*}$ \\
\hline L ankle dorsiflexion (kg) & $8.25(1.21)$ & $3.06(1.30)$ & 5.18 & 0.53 & $4.09-6.28$ & $<0.001^{*}$ \\
\hline $\mathrm{MIP}\left(\mathrm{mmH}_{2} \mathrm{O}\right)$ & $104.22(32.57)$ & $61.33(29.74)$ & 42.88 & 13.04 & $15.75-70.02$ & $<0.001^{*}$ \\
\hline $\mathrm{MEP}\left(\mathrm{mmH}_{2} \mathrm{O}\right)$ & $100.08(26.05)$ & $69.75(39.79)$ & 30.32 & 13.90 & $1.40-59.24$ & $0.004^{*}$ \\
\hline $\mathrm{R}$ deltoid CSA $\left(\mathrm{mm}^{2}\right)$ & $540.25(128.08)$ & $329.80(91.50)$ & 210.45 & 48.42 & $\begin{array}{l}109.43- \\
311.46\end{array}$ & $<0.001^{*}$ \\
\hline L deltoid CSA $\left(\mathrm{mm}^{2}\right)$ & $476.91(132.11)$ & $\begin{array}{c}359.70 \\
(104.38)\end{array}$ & 117.21 & 51.56 & $9.65-225.77$ & $0.03^{*}$ \\
\hline R FDS CSA $\left(\mathrm{mm}^{2}\right)$ & $538.55(107.29)$ & $438.00(83.95)$ & 100.66 & 41.74 & $13.59-187.74$ & $0.03^{*}$ \\
\hline L FDS CSA $\left(\mathrm{mm}^{2}\right)$ & $407.83(89.78)$ & $359.60(60.44)$ & 48.23 & 33.37 & $21.39-117.6$ & 0.2 \\
\hline R FDP CSA $\left(\mathrm{mm}^{2}\right)$ & $422.33(51.87)$ & $353.20(51.86)$ & 69.13 & 28.56 & $9.54-128.72$ & $0.03^{*}$ \\
\hline L FDP CSA $\left(\mathrm{mm}^{2}\right)$ & $534.75(74.22)$ & $490.30(75.46)$ & 48.23 & 33.37 & 21.39- 117.76 & 0.16 \\
\hline $\mathrm{R}$ rectus femoris $\operatorname{CSA}\left(\mathrm{mm}^{2}\right)$ & $539.41(129.49)$ & $\begin{array}{c}431.30 \\
(149.47)\end{array}$ & 108.11 & 59.44 & $\begin{array}{l}15.88- \\
232.12\end{array}$ & 0.08 \\
\hline $\mathrm{L}$ rectus femoris $\mathrm{CSA}\left(\mathrm{mm}^{2}\right)$ & $502.41(102.24)$ & $\begin{array}{c}429.20 \\
(159.27)\end{array}$ & 73.21 & 56.09 & $\begin{array}{c}43.80- \\
190.23\end{array}$ & 0.2 \\
\hline R TA CSA $\left(\mathrm{mm}^{2}\right)$ & 785.25 (128.86) & $\begin{array}{c}602.30 \\
(120.19)\end{array}$ & 182.95 & 53.53 & $71.27-294.62$ & $0.003^{*}$ \\
\hline L TA CSA $\left(\mathrm{mm}^{2}\right)$ & $793.91(112.67)$ & $\begin{array}{c}607.40 \\
(102.75)\end{array}$ & 186.51 & 46.38 & $\begin{array}{l}89.76- \\
283.26\end{array}$ & $0.001^{*}$ \\
\hline
\end{tabular}

BMI, body-mass index; R, right; L, left; MIP, maximum inspiratory pressure; MEP, maximum expiratory pressure; CSA, cross-sectional area; FDS, flexor digitorum superficialis; FDP, flexor digitorum profundus; TA, tibialis anterior muscle; *significant differences.

Table 3. Correlations between mean maximum inspiratory pressure (MIP), maximum expiratory pressure (MEP) and other parameters. All values are Spearman's rho.

\begin{tabular}{|c|c|c|c|c|c|c|c|c|c|c|c|}
\hline $\begin{array}{l}\text { Clinical } \\
\text { parameters } \\
\text { and muscle } \\
\text { power }\end{array}$ & sPAP & $\begin{array}{c}\text { 6-minute } \\
\text { walk } \\
\text { test }\end{array}$ & $\begin{array}{c}\text { emPHasis-10 } \\
\text { score }\end{array}$ & $\begin{array}{l}\text { R mean } \\
\text { shoulder } \\
\text { abduction }\end{array}$ & $\begin{array}{l}\text { L mean } \\
\text { shoulder } \\
\text { abduction }\end{array}$ & $\begin{array}{l}\text { R mean } \\
\text { grip }\end{array}$ & $\begin{array}{l}\text { L mean } \\
\text { grip }\end{array}$ & $\begin{array}{l}\text { R mean } \\
\text { knee } \\
\text { extention }\end{array}$ & $\begin{array}{l}\text { L mean } \\
\text { knee } \\
\text { extension }\end{array}$ & $\begin{array}{c}\text { R mean } \\
\text { ankle } \\
\text { dorsiflexion }\end{array}$ & $\begin{array}{c}\text { L mean } \\
\text { ankle } \\
\text { dorsiflexion }\end{array}$ \\
\hline MIP & -0.36 & -0.36 & -0.30 & $0.63^{* *}$ & $0.65^{* *}$ & $0.47 *$ & $0.47^{*}$ & $0.63^{* *}$ & $0.59 *$ & $0.59 *$ & $0.51^{*}$ \\
\hline MEP & 0.01 & -0.21 & -0.33 & $0.43^{*}$ & $0.50^{*}$ & $0.84^{* *}$ & $0.75^{* *}$ & $0.49 *$ & $0.55^{* *}$ & $0.54 * *$ & $0.55^{* *}$ \\
\hline CSA & $\begin{array}{l}\mathrm{R} \text { middle } \\
\text { deltoid }\end{array}$ & $\begin{array}{l}\text { L middle } \\
\text { deltoid }\end{array}$ & R FDS & L FDS & R FDP & L FDP & $\begin{array}{l}\mathrm{R} \text { rectus } \\
\text { femoris }\end{array}$ & $\begin{array}{l}\text { L rectus } \\
\text { femoris }\end{array}$ & $\begin{array}{l}\mathrm{R} \text { tibialis } \\
\text { anterior }\end{array}$ & $\begin{array}{l}\text { L tibialis } \\
\text { anterior }\end{array}$ & \\
\hline MIP & 0.38 & 0.28 & 0.18 & 0.24 & 0.39 & 0.23 & 0.31 & -0.02 & 0.37 & $0.56^{* *}$ & \\
\hline MEP & $0.55^{* *}$ & $0.61^{* *}$ & $0.63^{* *}$ & $0.43^{*}$ & $0.59 * *$ & $0.59 * *$ & 0.34 & 0.26 & $0.49 *$ & $0.72 * *$ & \\
\hline
\end{tabular}

$\mathrm{R}$, right; L, left; CSA, cross-sectional area; FDS, flexor digitorum superficialis; FDP, flexor digitorum profundus; ${ }^{p}<0.05 ;{ }^{*} p<0.001$. 
grip strength. This might be due to involving patients exclusively with the right dominance. However, the other muscles' results are parallel to the existing literature, showing an apparent decrease in skeletal muscle strength even in young patients with relatively mild disease and good functional status. Therefore, it would also be essential to document the long-term effects of skeletal muscle strength training on both peripheral skeletal muscles and respiratory muscles in these patients. Previously described changes in the skeletal muscles in patients with PAH are based on advanced molecular studies that showed changes in the muscle structure. Techniques used in these studies may be too advanced and costly to be used in current daily practice. Curiously, the changes in muscle structure in patients with PAH had never been investigated with musculoskeletal ultrasonography. Ultrasonography is a non-invasive and easy to apply method that does not take much time to perform. Therefore, it can be a suitable way to give an idea about the current status of both skeletal muscle and respiratory muscle strength in patients with PAH due to CHD. Especially ankle dorsiflexion and shoulder abduction, and their visualized muscles showed significant changes between groups and correlated with respiratory muscle strength according to this study's results. Therefore, they can be used as a surrogate to document and follow up muscle strength in patients with PAH due to CHD. However, patients with $\mathrm{PAH}$ consist of various etiologies, especially patients with CTEPH are significantly older. Advanced age will undoubtedly affect the skeletal muscle cross-sectional area in ultrasonography and skeletal muscle strength. A similarly designed study must be performed in all PAH subgroups for generalizability.

One limitation of this study is its cross-sectional nature. Although musculoskeletal ultrasonography shows promising leads about its relationship with respiratory muscle strength, its utility as a follow-up criterion is yet to be determined. Another limitation is the patient population. To keep the ultrasonography findings as homogenous as possible, younger patients with a certain diagnostic criterion of PAH have been recruited. One associated limitation is the lack of pulmonary function test data, since this patient population does not require regular pulmonary function testing. As discussed before, this approach is necessary to demonstrate the changes in muscle but revokes the chance to generalize this study's results to the all PAH population.

\section{Conclusions}

This study showed that in patients with pulmonary arterial hypertension due to CHD, respiratory muscle strength is significantly worse than healthy participants. Patients had also significantly worse skeletal muscle strength except for grip strength. Combined, the overall muscle involvement can be due to systemic muscular involvement, similar to other diseases that alter the cardiac output. The involvement of skeletal muscles can be shown reliably via ultrasonography in this patient population.

\section{References}

1. Galiè N, Humbert M, Vachiery J-L, et al. 2015 ESC/ERS Guidelines for the diagnosis and treatment of pulmonary hypertension: The Joint Task Force for the Diagnosis and Treatment of Pulmonary Hypertension of the European Society of Cardiology (ESC) and the European Respiratory
Society (ERS): Endorsed by: Association for European Paediatric and Congenital Cardiology (AEPC), International Society for Heart and Lung Transplantation (ISHLT). Eur Heart J 2016;37:67-119.

2. Spiesshoefer J, Orwat S, Henke C, et al. Inspiratory muscle dysfunction and restrictive lung function impairment in congenital heart disease: Association with immune inflammatory response and exercise intolerance. Int J Cardiol 2020;318:45-51.

3. Meyer FJ, Lossnitzer D, Kristen AV, et al. Respiratory muscle dysfunction in idiopathic pulmonary arterial hypertension. Eur Respir J 2005;25:125-30.

4. Aslan GK, Akinci B, Yeldan I, Okumus G. Respiratory muscle strength in patients with pulmonary hypertension: The relationship with exercise capacity, physical activity level, and quality of life. Clin Respir J 2018;12:699-705.

5. Riou M, Pizzimenti M, Enache I, et al. Skeletal and respiratory muscle dysfunctions in pulmonary arterial hypertension. J Clin Med 2020;9:410.

6. Laboratories ATSCoPSfCPF. ATS statement: guidelines for the six-minute walk test. Am J Respir Crit Care Med 2002;166: 111-7.

7. Andrews AW, Thomas MW, Bohannon RW. Normative values for isometric muscle force measurements obtained with handheld dynamometers. Phys Ther 1996;76:248-59.

8. Maayah MF, Al-Jarrah MD, El Zahrani SS, et al. Test-retest strength reliability of the Electronic Push/Pull Dynamometer (EPPD) in the measurement of the quadriceps and hamstring muscles on a new chair. Open J Int Med 2012;2:123-8.

9. Ashford RF, Nagelburg S, Adkins R. Sensitivity of the Jamar Dynamometer in detecting submaximal grip effort. J Hand Surg Am 1996;21:402-5.

10. American Thoracic Society/European Respiratory S. ATS/ERS Statement on respiratory muscle testing. Am J Respir Crit Care Med 2002;166:518-624.

11. Bhansing KJ, Van Rosmalen MH, Van Engelen BG, Vonk MC, Van Riel PL, Pillen S. Increased fascial thickness of the deltoid muscle in dermatomyositis and polymyositis: An ultrasound study. Muscle Nerve 2015;52:534-9.

12. Yaşar E, Adigüzel E, Kesikburun S, et al. Assessment of forearm muscle spasticity with sonoelastography in patients with stroke. Br J Radiol 2016;89:20160603.

13. Seymour JM, Ward K, Sidhu PS, et al. Ultrasound measurement of rectus femoris cross- sectional area and the relationship with quadriceps strength in COPD. Thorax 2009;64:418-23.

14. Sandberg C, Thilén U, Wadell K, Johansson B. Adults with complex congenital heart disease have impaired skeletal muscle function and reduced confidence in performing exercise training. Eur J Prev Cardiol 2015;22:1523-30.

15. Gil Obando LM, López López A, Avila CL. Normal values of the maximal respiratory pressures in healthy people older than 20 years old in the City of Manizales - Colombia. Colomb Med (Cali) 2012;43:119-25.

16. Sclauser Pessoa IM, Franco Parreira V, Fregonezi GA, et al. Reference values for maximal inspiratory pressure: a systematic review. Can Respir J 2014;21:43-50.

17. Aslan GK, Akinci B, Yeldan I, Okumus G. Respiratory muscle strength in patients with pulmonary hypertension: The relationship with exercise capacity, physical activity level, and quality of life. Clin Respir J 2018;12:699-705.

18. Marra AM, Arcopinto M, Bossone E, et al. Pulmonary arterial hypertension-related myopathy: an overview of current data and future perspectives. Nutr Metab Cardiovasc Dis 2015;25:131-9. 
19. Velez-Roa S, Ciarka A, Najem B, et al. Increased sympathetic nerve activity in pulmonary artery hypertension. Circulation 2004;110:1308-12.

20. Bauer R, Dehnert C, Schoene P, et al. Skeletal muscle dysfunction in patients with idiopathic pulmonary arterial hypertension. Respir Med 2007;101:2366-9.
21. Greutmann M, Le TL, Tobler D, et al. Generalised muscle weakness in young adults with congenital heart disease. Heart 2011;97:1164-8.

22. Kröönström LA, Johansson L, Zetterström A-K, et al. Muscle function in adults with congenital heart disease. Int J Cardiol 2014;170:358-63. 